\title{
EXPERIMENTAL STUDY ON CRYOGEN INJECTION INTO WATER
}

\author{
ZHANG, B. ${ }^{*}$ - ZHANG, X. D. - WU, W. Q. \\ Marine Engineering College, Dalian Maritime University \\ $I^{\text {st }}$ Linghai Road, Dalian, Liaoning, China \\ (phone: +86-411-8472-6002; fax: +86-411-8472-9012) \\ *Corresponding author \\ e-mail: zhangbindlmu@hotmail.com \\ (Received $8^{\text {th }}$ Mar 2017; accepted $7^{\text {th }}$ Jun 2017)
}

\begin{abstract}
Explosive boiling is a hyperactive boiling phenomenon, which is characterized by transient high heat flux. There are still few researches on the experimental comparative analysis on explosive boiling inducing by different cryogen liquid injection into water. In this paper, to advance our understanding of LNG (Liquefied Natural Gas), $\mathrm{LN}_{2}$ (Liquefied Nitrogen) and $\mathrm{LC}_{3} \mathrm{H}_{8}$ (Liquefied Propane) injection into water process, a visualization experimental system is built. Visualized results show that $\mathrm{LNG}$ and $\mathrm{LN}_{2}$ injection processes undergo a similar boiling, that is explosive boiling, which is characterized by bubbles cloud that strengthens heat transfer rate. $\mathrm{LC}_{3} \mathrm{H}_{8}$ injection into water triggers subcooled flow boiling. There is no significant breaking on the liquid cryogen column and without bubbles cloud. The maximum heat transferring flux can be over $1.9 \mathrm{MW} / \mathrm{m}^{2}$ in the condition of LNG injection into unconfined water and under the pressure of 7 bars. In order to investigate the determinant factors for explosive boiling occurring, instability of Rayleigh-Taylor, Kelvin-Helmholtz, Weber number and Marangoni convection are analyzed and used to explain the differences of maximum pressure and its occurring time in different experimental conditions such as injection depth into water, injection pressure, water temperature and injecting fluid. As a result, it is reasonable to conclude that if the relative velocity between cryogen and surrounding fluid is high enough, the breaking of liquid column or droplets will be defined by the Kelvin-Helmholtz instability and Weber number. And in subcooling mixture or pure substance injection process, the periphery of the vapor film near the head of column is considerably stronger than other regions in the effect of Marangoni convection at the beginning of column floating upwards or the ending of column going downwards. All of these can be seen as the key factors to improve heat transfer capacity and trigger explosive boiling.
\end{abstract}

Keywords: cryogen; explosive boiling; experimental study; instability; Malangoni effect; bubble behaviors

\section{Introduction}

Explosive boiling is a hyperactive boiling phenomenon, which is characterized by transient high heat flux. It is involved in many industry fields such as nuclear power, laser printing, microelectronic, fuel-coolant interactions (FCIs) and liquefied natural gas transportation. In liquefied natural gas transportation process, when discharging liquefied natural gas into water, direct contact heat exchange between liquefied natural gas and water with different temperatures about $180 \mathrm{~K}$ would occur. Under some certain conditions, liquefied natural gas vaporization rate will rapidly increase and the heat flux is higher than the critical heat flux (CHF). However, such rapid heat and mass transfer process would not always take place. So far, the determinants of this phenomenon have not been clearly confirmed.

Some experimental studies on discharging cryogen on water have been reported since 1971. Nakanishi and Reid (1971) conducted a series experiments on four different phases liquefied natural gas discharging on water. Experiments showed superheating occurred until homogeneous nucleation arises or until heterogeneous nucleation takes place on 
small active impurities. If the substrate was chemically like the cryogen spilled and the interfacial liquid had a low freezing point, then the explosive boiling may occur. Garland and Atinson (1971) found a similar conclusion as Nakanishi and Reid. They thought the composition of liquefied natural gas was important in noticing explosive boiling and that the presence of a hydrocarbon film on water increased the probability of explosive boiling occurrences. Enger (1972) reported a series tests of Shell, which conducted experiments on different composition liquefied natural gas discharging on hot water. The experiments showed that in environmental temperature, when methane content in liquefied natural gas was not less than $40 \%$ along with a few mole present n-butane, the explosive boiling may occur. But from Koopman et al. (1982) and Goldwire et al. (1983) reports, the explosive boiling may occur when methane content in liquefied natural gas as high as $90 \%$. Dahlsveen et al. (2001) conducted a process for liquefied natural gas injection. With changing composition of liquefied natural gas, experiments showed a much thicker vapor blanket and larger jet spreading angle (Dahlsveen et al., 2001; Khan and Noor, 2017)). Wen et al. (2006) conducted a series experiment of liquid nitrogen injection into water. With synchronized pressure and temperature measurement, heat transfer and pressurization rates had been establishing for application to a cryogenic engine. Pressurization rates of up to $5 \mathrm{bar} / \mathrm{s}$ were recorded, and heat transfer coefficients approximated for the latent heat transfer with assumed surface area were comparable to values found in other works on boiling heat transfer over very rough surfaces (Wen et al., 2006). Clarke et al. (2010) conducted a visualization study of liquid nitrogen injection into water with synchronized pressure and temperature measurement, to obtain insight into this phenomenon. It revealed a four-stage evolution of liquid nitrogen jet structure upon injection into water, with a thick vapor blanket forming around a liquid nitrogen core and break-up brought on predominantly through impact with the vessel wall. Maximum pressurization rate in excess of $350 \mathrm{bar} / \mathrm{s}$ were recorded and found to vary proportionally with injection pressure (Clarke et al., 2010; Anees et al., 2017).

Although previous studies have provided the experiences studies for explosive boiling, there are still few researches on the experimental comparative analysis on explosive boiling inducing by different cryogen liquid injection into water. In this paper, to advance our understanding of LNG (Liquefied Natural Gas), $\mathrm{LN}_{2}$ (Liquefied Nitrogen) and $\mathrm{LC}_{3} \mathrm{H}_{8}$ (Liquefied Propane) injection into water process, a visualization experimental system is built. Pressure profiles are obtained and synchronized with images for obtaining the heat transferring flux. Base on the instability theories, the effect of the material properties of cryogen liquid, water temperature and injection depth into water are investigated, which is in attempt to find the key factors caused explosive boiling in the process. The bubble behaviors are also analyzed and found some characteristics to explain the extremely rapid heat transferring rate of explosive boiling (Deng et al., 2017).

\section{Experimental apparatus}

The experimental rig (Fig. 1(a)-(b)) consists of a condensation system, a mixer tank, an injector, a visualized pressure tank (Fig. $1(\mathrm{c})$ ), and a data acquisition system (Zhang et al., 2015, 2016). 
(a)

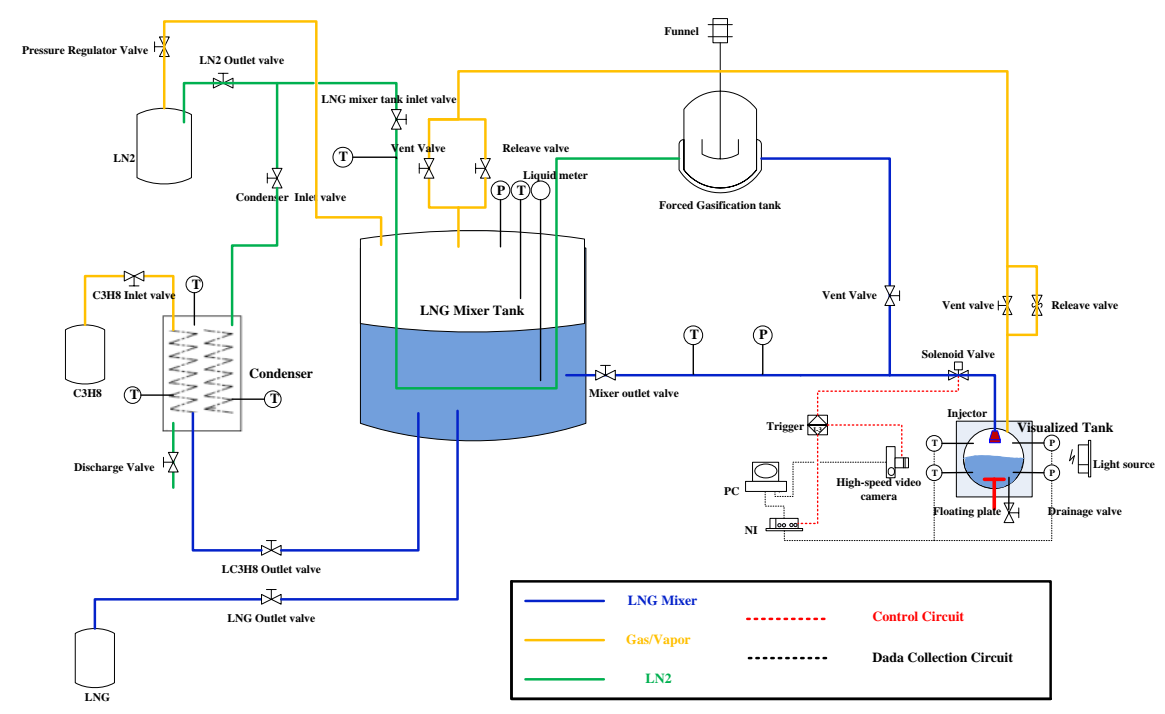

(b)

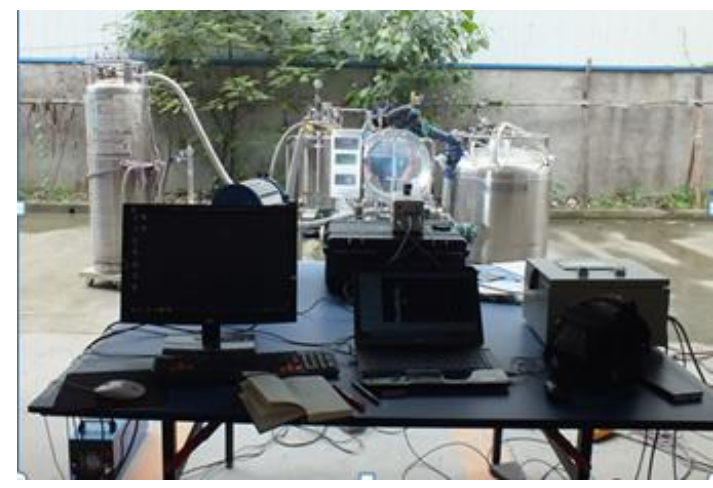

(c)

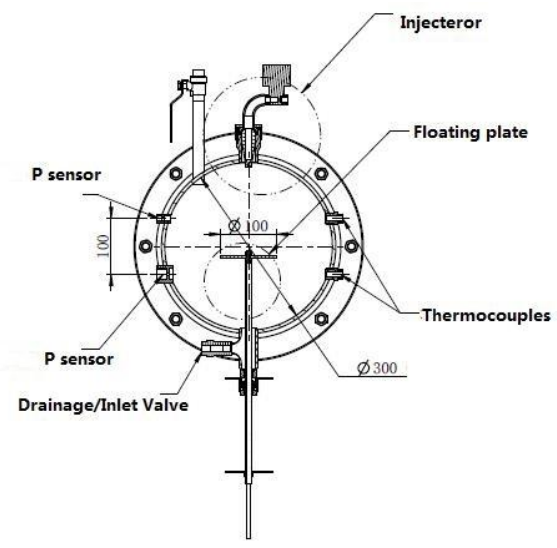

Figure 1. LNG injection setup and apparatus: (a) schematic of experimental rig; (b) picture of apparatus; (c) positions of all sensors in tank.

$\mathrm{LN}_{2}$ and LNG are separately delivered through insulated pipe and outlet valve from a controllable pressure Dewar. Out of necessity, LNG injection must occur below its bubbling point, which can be conducted in the LNG mixer tank by $\mathrm{LN}_{2}$. After the $\mathrm{LN}_{2}$ delivered through LNG mixer tank, the temperature of LNG in mixer tank can be maintained at $100 \mathrm{~K}( \pm 5 \mathrm{~K})$, that is $\sim 10 \mathrm{~K}$ below the $\mathrm{LNG}$ bubbling point. The pressure of LNG mixer tank equals to injection pressure, which is controlled by manually adjusting the pressure regular valve on $\mathrm{LN}_{2}$ Dewar. Because the propane gas is storage in the gaseous phase, before injecting, it must be condensed into liquefied propane, which can be conducted in a similar way like LNG cooling process. In the $\mathrm{LN}_{2}$ injection process, the system must be improved and the $\mathrm{LN}_{2}$ Dewar outlet valve to be directly combined with the mixer outlet valve. Where after, the cryogen liquid is delivered to an ASCO intrinsically safe type cryogenic solenoid valve, which controls the opening of the injector. The injector is made of a $25 \mathrm{~mm}$ length of steel pipe with an inside diameter of 5 $\mathrm{mm}$. To prevent heat leakage, the all cryogenic liquid pipes are made of double insulated vacuum steel pipe, and before experiments, the pipes are precooled by $\mathrm{LN}_{2}$ and the time is not less than $10 \mathrm{~min}$. 
The visualized pressure tank is a stainless cylinder of diameter $300 \mathrm{~mm}$ and depth $150 \mathrm{~mm}$ with Perspex windows clamped onto each end. The safety valve and vent valve are fitted on the tank to prevent pressurization above 40 bars and can vent the vapor respectively. Two T-type sheathed thermocouples of $10 \mathrm{~mm}$ in diameter, $140 \mathrm{~mm}$ in length, with accuracy of $0.5 \%$ FS and two high frequency dynamic pressure sensors of $4 \mathrm{~mm}$ in diameter, $10 \mathrm{~mm}$ in length, with accuracy of $0.5 \%$ FS with minimum response time of $4 \mu$ s are used to measure the temperatures and pressure within the tank. The positions of all sensors are illustrated in Fig. 1(c).

The boiling process of LNG into water is recorded by a high-speed camera (Svsi Gigaview) with the frame rate of 532 17045 frames per second. In this series experiments, the frame rate is 1000 frames per second, and frame size is $640 \times 480$ pixels. A $575 \mathrm{~W}$ quartz metal halide light source is added to improve the qualities of the frames. The camera and the image acquisition software are triggered by the leading edge of a $5 \mathrm{~V}$ pulse generated within PLC (Programmable Logic Controller) hardware, programmed and controlled by the operator. The image acquisition software comes with the camera and can set the image acquisition rate, image pixel and exposure time. The same pulse triggers the National Instruments Data-Acquisition hardware and LabVIEW to acquire and store both pressure and temperature data, at a rate of 10,000 samples per second. Another 5V pulse is generated after $100 \mathrm{~ms}$ within the PLC, which is used to trigger the ASCO solenoid valve opening. The opening time is dependent on the trigger pulse width, which can be set manually within the PLC.

\section{Experimental results}

By controlling the $\mathrm{LN}_{2}$ Dewar outlet pressure and outflow, the different injection pressures and thermodynamic states of cryogen can be adjusted. A number of cryogen injection experiments are conducted, of $\mathrm{LNG}, \mathrm{LN}_{2}$ and $\mathrm{LC}_{3} \mathrm{H}_{8}$, into water of different temperature and depth. The parameters for experiments are shown in Table 1. The LNG component concentration is provided by the LNG supplying company. By adjusting the location of floating plate under water, the cryogen injection into water depth can be controlled. Injecting during time can be controlled by the power time of ASCO solenoid valve.

Table 1. Experiment run parameters

\begin{tabular}{c|c|c|c|c|c|c|c}
\hline Run & $\begin{array}{c}\text { Component } \\
\text { Concentration } \\
\mathbf{C H}_{4}: \mathbf{C}_{\mathbf{2}} \mathbf{H}_{\mathbf{6}}: \\
\mathbf{C}_{\mathbf{3}} \mathbf{H}_{\mathbf{8}}: \mathbf{O S} \\
(\mathbf{v} / \mathbf{v} \mathbf{\%})\end{array}$ & $\begin{array}{c}\text { Water } \\
\text { Temperature } \\
(\mathbf{K})\end{array}$ & $\begin{array}{c}\text { Floating } \\
\text { Plate } \\
\text { Location } \\
\text { under } \\
\text { Water } \\
(\mathbf{m m})\end{array}$ & $\begin{array}{c}\text { Injection } \\
\text { Pressure } \\
(\mathbf{B a r})\end{array}$ & $\begin{array}{c}\text { Max. } \\
\text { Injection } \\
\text { During } \\
\text { time (ms) }\end{array}$ & $\begin{array}{c}\text { Max. } \\
\text { Pressure } \\
(\mathbf{B a r})\end{array}$ & $\begin{array}{c}\text { Pressure } \\
\text { Occurring } \\
\text { Time after } \\
\text { Injection } \\
(\mathbf{m s})\end{array}$ \\
\hline 1 & $97: 2: 0.5: 0.5$ & 290 & 210 & 7 & 200 & 3.01 & 6553 \\
2 & $97: 2: 0.5: 0.5$ & 290 & 140 & 7 & 200 & 1.61 & 6284 \\
3 & $97: 2: 0.5: 0.5$ & 290 & 210 & 5 & 200 & 1.64 & 5558 \\
5 & $97: 2: 0.5: 0.5$ & 308 & 140 & 7 & 200 & 1.00 & 6442 \\
6 & $\mathrm{C}_{3} \mathrm{H}_{8}: 100 \%$ & 303 & 200 & 4 & 300 & 0.23 & 12465 \\
\hline
\end{tabular}




\section{Discussion}

\section{Heat transferring flux}

As Table 1 shown, the maximum pressure occurs in run 1, which injection pressure is one of the highest, water temperature is one of the lowest and floating plate location under water is bottommost. The pressure of the visualized pressure tank is shown in Fig. 2(a) over a $10 \mathrm{~s}$ timescale and additionally in Fig. 2(b) for the maximum pressure occurring time over $100 \mathrm{~ms}$ timescale (from $5400 \mathrm{~ms}$ to $5499 \mathrm{~ms}$ after injection). In Fig. 2(a), the pressure data is recorded by the high frequency dynamic pressure sensors of $10 \mathrm{~mm}$ in length, before trigger activating $100 \mathrm{~ms}$. In Fig. 2(b), the pressurization is extremely rapid at $\sim 300 \mathrm{bar} / \mathrm{s}$. Using TNT equivalent model can simplify the process so that the heat transfer coefficient can be obtained. The following expressions relating the maximum pressure and the heat transfer flux (Zhang et al., 2015).

$$
\begin{gathered}
W_{T N T}=k \frac{a W_{L N G} Q_{L N G}}{Q_{T N T}} \\
\Delta P=P_{0}\left(3.9 Z^{-1.82}+0.5 Z^{-1}\right) \\
Z=R \cdot W_{T N T}^{-1 / 3} \\
H_{R P T}=L_{V} \cdot W_{L N G} /\left(S \cdot t_{d}\right)
\end{gathered}
$$

Where $W_{T N T}$ is TNT equivalent, $\mathrm{kg} ; W_{L N G}$ is LNG mass which is fragmented, $\mathrm{kg} ; k$ is surface burst coefficient; $a$ is equivalent coefficient; $Q_{L N G}$ is bursting heat, J; $Q_{T N T}$ is TNT bursting heat, $\mathrm{J} ; \Delta P$ is maximum pressure value, $\mathrm{Pa} ; R$ is distance from pressure sensor, $\mathrm{m} ; H_{R P T}$ is heat transfer flux, $\mathrm{W} / \mathrm{m}^{2} ; L_{V}$ is latent heat of $\mathrm{LNG}, \mathrm{J} / \mathrm{kg} ; t_{d}$ is the duration time of pressure increasing, s. It is $\sim 10 \mathrm{~ms}$ obtained from the Fig. 2. Combining Eqs. (1)-(4), the maximum heat transferring flux can be over $1.9 \mathrm{MW} / \mathrm{m}^{2}$. It is $\sim 7.8$ times bigger than the theoretical limit of heat transferring flux of the pure liquefied methane nucleate boiling $\left(0.244 \mathrm{MW} / \mathrm{m}^{2}\right)$ (Nail, 1999).

(a)

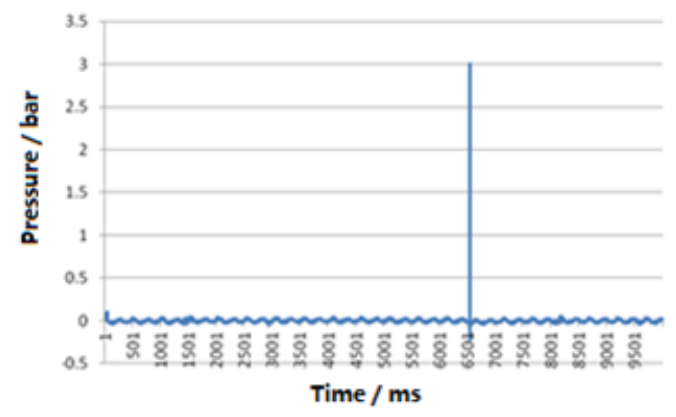

(b)

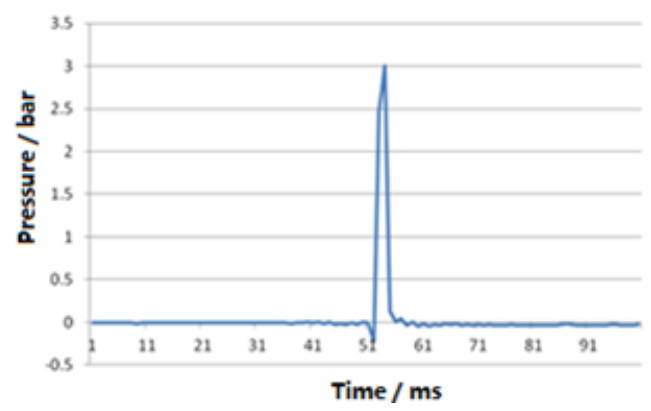

Figure 2. Pressure curve correspondent to run 1 using the P sensor under water: (a) the time is from 0 ms to $10000 \mathrm{~ms}$ after injection; (b) the time is from $5400 \mathrm{~ms}$ to $5499 \mathrm{~ms}$ after injection). 


\section{Theoretical analysis about instability}

As cryogen injecting into water, the interface between cryogen and water would be with wave. If disturbances of all wavelengths are present, there will be some disturbances at small wave number and long wavelength that will amplify and cause the interface to be unstable. There are four main instability theories can be used to explain the explosive boiling mechanism of cryogen injection into water.

Rayleigh-Taylor instability (Van, 1992; Byoung et al., 2015; Awasthi, 2013)

It is the instability of an interface between two fluids of different densities which occurs when the lighter fluid is pushing the heavier fluid. If the energy of interface tension is higher than the sum of kinetic energy of fluctuations and potential energy, the interface will be with a stable vapor film. Otherwise, the interface will be unstable and the vapor film will be broken because of the Rayleigh-Taylor instability. It takes more effect on the leading end than the side of liquid column. The most dangerous wavelength is given by:

$$
\lambda_{D}=2 \pi \sqrt{\frac{3 \sigma}{\left|\rho_{c l}-\rho_{w}\right| g}}
$$

Where $\lambda_{D}$ is the most dangerous wavelength, $\mathrm{m} ; \rho_{c l}$ is liquid cryogens density, $\mathrm{kg} / \mathrm{m}^{3}$; $\rho_{w}$ is circumstance fluid density, $\mathrm{kg} / \mathrm{m}^{3} ; \sigma$ is the interfacial tension, $\mathrm{N} / \mathrm{m} ; g$ is the gravitational acceleration, $\mathrm{m} / \mathrm{s}^{2}$.

Kelvin-Helmholtz instability (Van, 1992; Awasthi et al., 2012; Hyun and Junseok 2015 )

When there is a sufficiently large velocity difference across a small amplitude perturbed interface between two fluids, the interface is unstable. This interfacial instability is known as the Kelvin-Helmholtz instability. The instability occurs when the destabilizing effect of shear across the interface overcomes the stabilizing effect of gravity and/or surface tension. It takes obvious effect on the side of liquid column. If a specific disturbance wavelength is imposed on the system, the interface will be unstable for:

$$
\begin{gathered}
\left|\overline{u_{c l}}-\overline{u_{w}}\right|>u_{c} \\
u_{c}=\sqrt{\frac{2 \pi \sigma\left(\rho_{c l}+\rho_{w}\right)}{\lambda_{D} \rho_{c l} \rho_{w}}+\frac{g \lambda_{D}\left(\rho_{c l}-\rho_{w}\right)\left(\rho_{c l}+\rho_{w}\right)}{2 \pi \rho_{c l} \rho_{w}}}
\end{gathered}
$$

If $g$ is set to zero, we get the dispersion relation for a vertical interface, which implies that:

$$
u_{c}=\sqrt{\frac{2 \pi \sigma\left(\rho_{c l}+\rho_{w}\right)}{\lambda_{D} \rho_{c l} \rho_{w}}}
$$

The most dangerous wavelength is given by: 


$$
\lambda_{D}=\frac{2 \pi \sigma\left(\rho_{c l}+\rho_{w}\right)}{u_{c}^{2} \rho_{c l} \rho_{w}}
$$

Where $u_{c}$ is critical velocity, $\mathrm{m} / \mathrm{s} ; u_{c l}$ is liquid cryogens velocity, $\mathrm{m} / \mathrm{s} ; u_{w}$ is circumstance fluid velocity, $\mathrm{m} / \mathrm{s}$.

Weber number (Van, 1992)

As cryogen injecting into water, the velocity difference between the two fluids will produce tangential stress on the interface. If the tangential stress is bigger than the surface tension, the cryogen column will be broken into liquid droplets. The minimum diameter of stable liquid droplets is dependent on the magnitude of shear stress, which will be increased with the velocity difference increasing. The minimum characteristic length of stable liquid column or droplets is given by:

$$
\begin{gathered}
L=\frac{W e_{c} \sigma}{\rho_{w}\left(\overline{u_{c l}}-\overline{u_{w}}\right)^{2}} \\
W e_{c}=\frac{8}{f}
\end{gathered}
$$

Where $L$ is minimum characteristic length of stable liquid column or droplets, $\mathrm{m} ; W e_{c}$ is critical Weber number; $f$ is friction coefficient, $f=0.44$ when $500<R e<10^{5}$.

Marangoni effect (Tang, Zhu, and Sun, 2013)

Marangoni effect is caused by the heterogeneity of the surface tension near interface of two fluids with different temperature. In subcooled flow boiling, the surface tension gradient along two fluids contact interface is raised from the temperature difference in the vapor film around the liquid cryogen column, which leads to the tangential stresses of $\tau_{\mathrm{cl}}$ and $\tau_{\mathrm{cv}}$ on liquid cryogen side and vapor cryogen side at the interface respectively. Due to reaction of the stresses of $\tau_{\mathrm{cl}}$ and $\tau_{\mathrm{cv}}$, the liquid and vapor phase of cryogen were accelerated and the Marangoni effect formed near the interface. Fig. 3 shows a schematic diagram to describe the Marangoni effect near a smooth and stable vapor film caused by temperature gradient and the force balance in tangential direction on the cryogen surface. Under steady state condition, the balance of forces at the interface is:

$$
\tau_{c l}+\tau_{c v}=\frac{d \sigma}{d T} \Delta T / \delta
$$

Moreover, the shear stress on vapor side at the interface $\tau_{\mathrm{cv}}$ can be neglected since the most gases viscosity is much smaller. Therefore, the simplification of (Eq.12) is:

$$
\tau_{c l}=\frac{d \sigma}{d T} \Delta T / \delta
$$


Strength of Marangoni effect can be characterized by the Marangoni number

$$
M a=\left|\tau_{c l} \frac{\delta^{2}}{\alpha_{c l} \mu_{c l}}\right|
$$

Where $\tau_{\mathrm{cl}}$ is shear stress on liquid side, $\mathrm{N} / \mathrm{m}^{2} ; \tau_{\mathrm{cv}}$ is shear stress on vapor side, $\mathrm{N} / \mathrm{m}^{2} ; \delta$ is the characteristic length of interface, $\mathrm{m} ; \alpha_{\mathrm{cl}}$ is thermal diffusivity of cryogen liquid, $\mathrm{m}^{2} / \mathrm{s} ; \mu_{\mathrm{cl}}$ is the dynamic viscosity of cryogen liquid, $\mathrm{kg} / \mathrm{s} \bullet \mathrm{m}$.

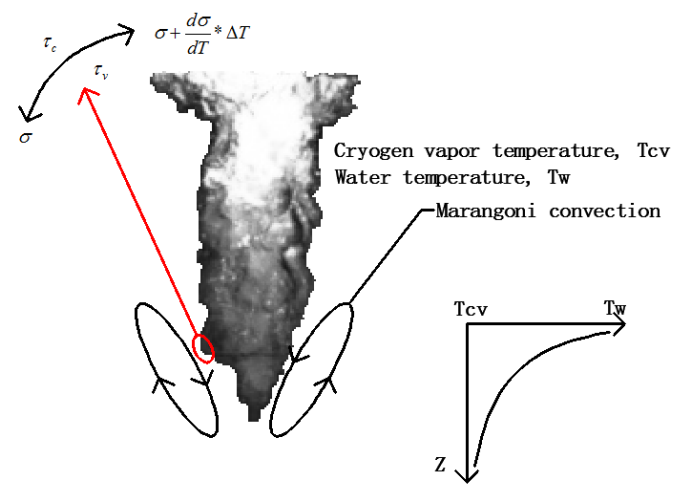

Figure 3. Schematic diagram of Marangoni convection near the vapor film (The original image is $3 d$ in Fig. 5)

\section{Effect of injection depth into water}

Comparing run 1 and run 2 , the maximum pressure of run 2 decreases $\sim 46.5 \%$, and the time of maximum pressure occurs $\sim 270 \mathrm{~ms}$ ahead. Besides the location of floating plate, the other parameters of experiments are similar. As a result of that, the mainly reason for the differences between the two runs is the depth of injection into water. According to the Kelvin-Helmholtz instability and critical Weber number theory, as (Eq.6) is satisfied, the interface between cryogen and water will become unstable and the liquid column of cryogen will be broken into small droplets, which diameter is equal to the $\lambda_{D}$ or $L$ is separately calculated by (Eq.9) and (Eq.10). The effective heat transferring area is remarkably increasing. But if the liquid column of cryogen impinges the floating plate, $\left|\overline{u_{c l}}-\overline{u_{w}}\right|$ will be reduced to zero, liquid column of cryogen stop breaking into droplets in the effect of instability. But the collision process will become complicated. The droplets of cryogen may be undergone two contradicting processes that are coalescence and breakup. The maximum pressure of run 2 is lower than run 1, it implies that the coalescence effect in the collision process has an obvious effect, that can decrease the heat transferring capacity and boiling rate. From another point of view, because the injection depth into water is unconfined, the breakup during time of liquid droplets or column in run 1 is longer than run 2 which induces the maximum pressure occurring time being aback.

As a result, as cryogen releasing or injecting into water, the maximum pressure or boiling rate will be reduced by confining the water depth, which can be used to limit explosive boiling occurring. 


\section{Effect of injection pressure}

Comparing run 1 and run 3 , the $\overline{u_{c l}}$ in run 3 is smaller than run 1 , as a result, the maximum pressure of run 3 is $\sim 45.5 \%$ smaller than run 1 . It implies the heat transfer capacity and boiling rate of run 3 are both smaller than run 1 . There are two main reasons for the difference of the maximum pressure. Firstly, in the effect of Kelvin-Helmholtz instability, as (Eq.6) is satisfied, the liquid column of cryogen will breakup into droplets, and the mean diameter of droplets is equal to the most dangerous wavelength $\lambda_{D}$, which will be reduced with $\left|\overline{u_{c l}}-\overline{u_{w}}\right|$ increasing. Secondly, basing on the Weber number theory, as $\left|\overline{u_{c l}}-\overline{u_{w}}\right|$ increasing, the tangential stress on the interface will increase, which will decrease the minimum characteristic length $L$ that means the liquid droplets will break into much smaller droplets. The heat transferring area will dramatically increase, which implies both boiling rate and heat transferring capacity will substantial increase.

Furthermore, the occurring time of maximum pressure is $\sim 1000 \mathrm{~ms}$ earlier than run 1 . It means the breakup duration time of liquid column and droplets of cryogen in run 3 is shorter than run 1. In an another word, the time of liquid column and droplets stopping breaking into smaller diameter droplets in run 3 is earlier than run 1.

In conclusion, the injection pressure is related to the boiling rate. As the injection pressure increasing, the maximum pressure will increase and its occurring time will be advanced, which will increase the probability of explosive boiling.

\section{Effect of water temperature}

Comparing run 2 and run 4 , the water temperature of run 4 is higher than run 2, as a result of that the maximum pressure of run 4 is $\sim 37.8 \%$ smaller than run 2 . Fig. $4 a$ shows the circumstance fluid is vapor film, whose temperature is equal to the water temperature of run 2. There is a hypothesis the water temperature is low enough that there is no evaporation occurring, so the circumstance fluid is water as the Fig. $4 b$ showing. Both the most dangerous wavelengths in Rayleigh-Taylor instability in Fig. $4 a-b$ are approximately equal. But the most dangerous wavelengths in Kelvin-Helmholtz instability and the minimum characteristic lengths in Weber Number theory in Fig. 4a-b varies greatly. It implies, as the concentration of vapor in the interface between cryogen and water decreasing, the most dangerous wavelengths in Kelvin-Helmholtz instability and the minimum characteristic lengths in Weber Number theory dramatically decreasing, which intensifies the cryogen column and droplets breaking up into much smaller droplets and promotes higher heat transferring rate and boiling intensity.

Furthermore, the maximum pressure occurring time of run 4 is a little bit later than run 2. That is because, as the water temperature increasing, the initial film boiling rate and vapor film thickness in run 4 are separately higher than run 2 , which will decrease relative velocity and the instability effects of the interface, as a result of that it needs much more time to trigger cryogenic column breaking into droplets and dramatically decreasing heat transferring capacity. 


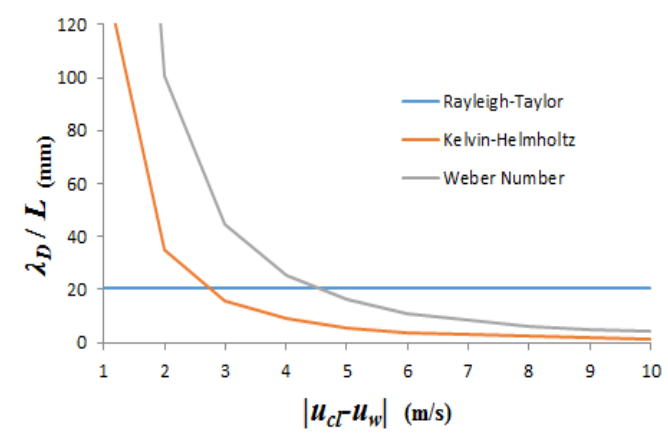

(a) Circumstance fluid is vapor of cryogen

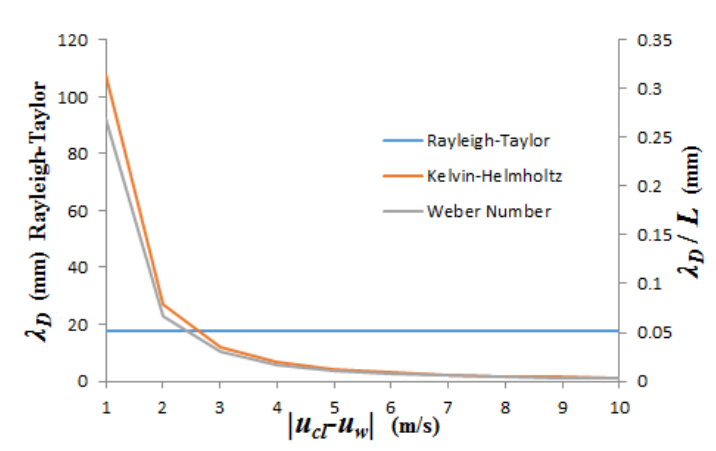

(b) Circumstance fluid is water

Figure 4. Most dangerous wavelength in Rayleigh-Taylor instability and Kelvin-Helmholtz instability, and minimum characteristic length in Weber Number Theory

As a result, if the water temperature is increasing, the instability of Kelvin-Helmholtz and Weber number will be reduced. The diameter of droplets breaking from column will be increased. The effective area of heat transferring will be considerably decreased, which will reduce the heat transferring capacity and have less opportunity to trigger explosive boiling.

Base on the thermodynamics theory, if the temperature of water is higher than Leidenfrost temperature of cryogen (Van, 1992), there will be a film boiling. The Leidenfrost temperature for methane, ethane, propane and nitrogen are $161 \mathrm{~K}, 249 \mathrm{~K}$, $312 \mathrm{~K}$ and $126 \mathrm{~K}$, respectively. And only if the water temperature is equal or slightly greater than the superheat limit temperature of cryogen $\left(T_{\text {superheat }}<T_{\text {water }}<1.1 T_{\text {superheat }}\right)$, the explosive boiling will be triggered (Luketa-hanlin, 2006; Ashraf et al., 2017). The superheat limit temperature for methane, ethane, propane and nitrogen are $168 \mathrm{~K}$, $269 \mathrm{~K}, 326 \mathrm{~K}$ and $110 \mathrm{~K}$, respectively. The superheat limit temperature of hydrocarbon mixtures is approximately the mole fraction average of the superheat limit temperatures of the components (Porteous and Blander, 1975). But the water temperature is not the only factor for triggering explosive boiling. Because, in run 1, run 2 and run 3, it has the same condition of water, the maximum pressures have great differences. There should be some other factors for triggering explosive boiling, such as injection pressure, injection depth into water and working substances (Zhang et al., 2016).

\section{Effect of injecting cryogen}

From Table 1, the run 1, 5 and 6 are separately used $\mathrm{LNG}, \mathrm{LC}_{3} \mathrm{H}_{8}$ and $\mathrm{LN}_{2}$. It shows that the maximum pressure of run 1 is $\sim 18.9 \%$ bigger than run 6 , and $\sim 13$ times of run 5. Furthermore, the maximum pressure occurring time of run 6 is earlier than run 1 , and much earlier than run 5 . There are three main reasons.

(1) LNG is mixture. In the process of LNG injecting, the LNG column will be heated by surrounding water and some of it will boil into vapor phase. As a result of that, liquid LNG components will change and bubble point changes correspondingly. On the effect of Marangoni effect, the surface tension gradient along two fluids contact interface is raised from the bubble point difference in the vapor film around the liquid cryogen column, which leads to the tangential stresses. If the tangential 
stress is bigger than the surface tension, the cryogen column will be broken into liquid droplets or big droplets further break into small ones. But $\mathrm{LC}_{3} \mathrm{H}_{8}$ and $\mathrm{LN}_{2}$ are both pure substances whose boiling temperatures only relate to the pressure. So the surface tension gradient along two fluids contact interface is raised from the initial degree of subcooling. In run 6 , the $\mathrm{LN}_{2}$ is nearly saturation liquid, so there should be less Marangoni effect in this process. In run 5, the $\mathrm{LC}_{3} \mathrm{H}_{8}$ has $\sim 120$ degrees of subcooling, so there should be an obvious Marangoni effect. That can be seen from the Fig. 5. Comparing 1a 1f and 2a 2f, the pattern of LNG bubbles have a less value of $L_{\mathrm{c}} / D_{\mathrm{c}}$ than $\mathrm{LN}_{2}$ bubbles ( $L_{\mathrm{c}}$ is the length of the bubbles pattern; $D_{\mathrm{c}}$ is the diameter of the bubbles pattern). It means LNG column suffers much more tangential stress than the $\mathrm{LN}_{2}$, which makes more bubbles break up from side than the leading end. And from $3 \mathrm{a} \sim 3 \mathrm{f}$, the $\mathrm{LC}_{3} \mathrm{H}_{8}$ bubbles generate more from side than the leading end of liquid column. It means the Kelvin-Helmholtz instability and Marangoni convection occupies leading position on the process of column breaking into droplets.

(2) The degrees of subcooling of $\mathrm{LC}_{3} \mathrm{H}_{8}$ is much more than LNG and $\mathrm{LN}_{2}$, as a result of that, it needs more time and heat to be saturated, and in turn, the maximum pressure occurring time of run $5\left(\mathrm{LC}_{3} \mathrm{H}_{8}\right)$ is obviously later than the other runs of 1 $(\mathrm{LNG})$ and $6\left(\mathrm{LN}_{2}\right)$. Furthermore, the maximum pressure occurring time of run 1 is a little later than run 6. On one side, the density of $\mathrm{LNG}$ is less than $\mathrm{LN}_{2}$, which causes the relative velocity of $\mathrm{LNG}$ is slower than $\mathrm{LN}_{2}$. On the effect of instabilities of Kelvin-Helmholtz and critical Weber number, the intensity of breaking of LNG is not as strong as $\mathrm{LN}_{2}$. So the maximum pressure occurring time of LNG is not as early as $\mathrm{LN}_{2}$. On the other side, the $\mathrm{LNG}$ is subcooling cryogen and the $\mathrm{LN}_{2}$ is saturate substance. In the process of LNG injection, it needs some time to heat it to be saturated, though the time will be substantially short as the difference of temperatures of LNG and water being huge.

(3) From the above analysis, the Marangoni convection has an obvious effect on strengthen heat transferring rate. Base on the instabilities of Rayleigh-Taylor, Kelvin-Helmholtz and critical Weber number theory, the maximum pressure detected in $\mathrm{LN}_{2}$ test (run 6) should be higher than $\mathrm{LNG}$ test (run 1). But the real results are just the opposite. The mainly reason is the effect of Marangoni effect. As the relative velocity becoming slower and slower, the Marangoni convection takes the leading position and the instability effects of Rayleigh-Taylor, Kelvin-Helmholtz and critical Weber number theory becomes weaker and weaker. Because of the effect of Marangoni convection prolonging the breaking time of droplets, the maximum pressure and the occurring time of maximum pressure in run 1 is separately higher and later than run 6 .

\section{Bubble behaviors analysis}

From these images of 1a 1f and 2a 2f in Fig. 5, the structure and pattern of bubbles have a similar developing process in run 1 and run 6 . It can be characterized in three main stages (Zhang et al., 2015; Clarke et al., 2010; Dahlsveen et al., 2001).

(1) Stable film boiling stage: from the images of $1 \mathrm{a} \sim 1 \mathrm{~b}$ and $2 \mathrm{a} \sim 2 \mathrm{~b}$, it can be seen that liquid cryogen flashes as it impinges into water and forms a vapor void. Because the injection process is likely to continue for some time, the following liquid cryogen is injected into the void created by the former boiling cryogen. A velocity difference forms on the relatively stable vapor film between liquid cryogen and water, but the water outside vapor film is nearly static. So the liquid cryogen inside vapor film is 
moving downwards under a high speed. There is no significant breaking on the liquid cryogen column, although formation of waves on the vapor film due to the instability of dynamics is observed.

(2) Bubbles cloud generation stage: as the liquid cryogen continuously moving downwards, on the effect of instabilities of Rayleigh-Taylor, Kelvin-Helmholtz and critical Weber number, the shearing stress is bigger than the surface tension, and then the ligaments and fragmentations take place. In the images of $1 \mathrm{c} \sim 1 \mathrm{~d}$ and $2 \mathrm{c} \sim 2 \mathrm{~d}$, it shows the vapor film becomes thinner and lighter. There is a cloud of bubbles form on the head and the side of the column (Wen et al., 2006). The cloud of bubbles is extremely unstable; some of them will be coalescence and others will be continuously breaking up into smaller ones. The heat transferring rate will be dramatically increasing as a result of the bubbles growing up and breaking which enhances the heat convection between cryogen and water. On the effect of Marangoni convection, the images of 1c 1d show the bubbles cloud has a more unstable vapor film nearby the head of column than $2 \mathrm{c} \sim 2 \mathrm{~d}$.

(3) Buoyancy taking over stage: in the images of 1e 1f and 2e 2f, it shows that, in the last stage of injections, the buoyancy force will take over. The bubbles cloud gradually disappears and forms much bigger bubbles that are so stable that they cannot be broken up again in the upwards moving process. Comparing the images of $1 \mathrm{e} \sim 1 \mathrm{f}$ and $2 \mathrm{e} 2 \mathrm{f}$, the bubbles cloud maintain longer in run1, because of the effect of Marangoni convection.

The images of 3a 3f in Fig. 5 shows a different structure and pattern of bubbles. It can be characterized in two main stages.

(1) Stable flow boiling stage: in all images of run 5 , the $\mathrm{LC}_{3} \mathrm{H}_{8}$ column has a relatively obvious shape and the boiling is not as violent as run 1 and 5. Most of it has no significant breaking except the periphery of the vapor film near the head of column in the image of $3 \mathrm{~d}$. There are three main reasons.

Firstly, the water temperature is $\sim 303 \mathrm{~K}$, which is less than the superheat limit temperature of $\mathrm{LC}_{3} \mathrm{H}_{8}$. As a result of that, the explosive boiling would have less opportunity to take place and it undergoes a relatively stable boiling, that is subcooled flow boiling.

Secondly, because of the $\sim 120$ degrees of subcooling, after $\mathrm{LC}_{3} \mathrm{H}_{8}$ injecting into water, it needs much more time to be heated to the saturate temperature by surrounding water. As a result of that, it can maintain an obvious liquid column shape in a relative long time. Because the water temperature is less than the Leidenfrost temperature of $\mathrm{LC}_{3} \mathrm{H}_{8}$, the vapor film of run 6 is not as stable as run 1 and 5, and the surrounding fluid will be water. The relative velocity, which is related to density difference between $\mathrm{LC}_{3} \mathrm{H}_{8}$ and surrounding fluid, is less than run 1 and 6 . Basing on the instability of Kelvin-Helmholtz and Weber number, as relative velocity decreasing, the most dangerous wavelength and minimum characteristic length will be considerably increasing. It implies the $\mathrm{LC}_{3} \mathrm{H}_{8}$ will become more and more stable and suffer less from the instability of Kelvin-Helmholtz and Weber number.

Finally, $\mathrm{LC}_{3} \mathrm{H}_{8}$ is $\sim 120$ degrees of subcooling. As a result, in subcooled flow boiling, the surface tension gradient along two fluids contact interface is raised from the temperature difference in the vapor film around the liquid cryogen column, which leads to the tangential stresses on liquid cryogen side and vapor cryogen side at the interface respectively. When the stresses accrete to higher than the surface tension, the 
Marangoni effect will take place and some of the liquid column will breakup into small droplets, which can be seen in the image of $3 \mathrm{~d}$. From that image, we can also know that the periphery of the vapor film near the head of column is considerably stronger than other regions in the effect of Marangoni.

(2) Buoyancy taking over stage: in the images of $3 \mathrm{e} \sim 3 \mathrm{f}$, it shows that, in the last stage of injections, the buoyancy force will take over. The evaporating bubbles move upwards in a higher speed than the $\mathrm{LC}_{3} \mathrm{H}_{8}$ column and begin to separate from it. After that, the $\mathrm{LC}_{3} \mathrm{H}_{8}$ column still staying in the water is not broken again and some of it maintains liquid phase until floating on the water and forms liquid pool.
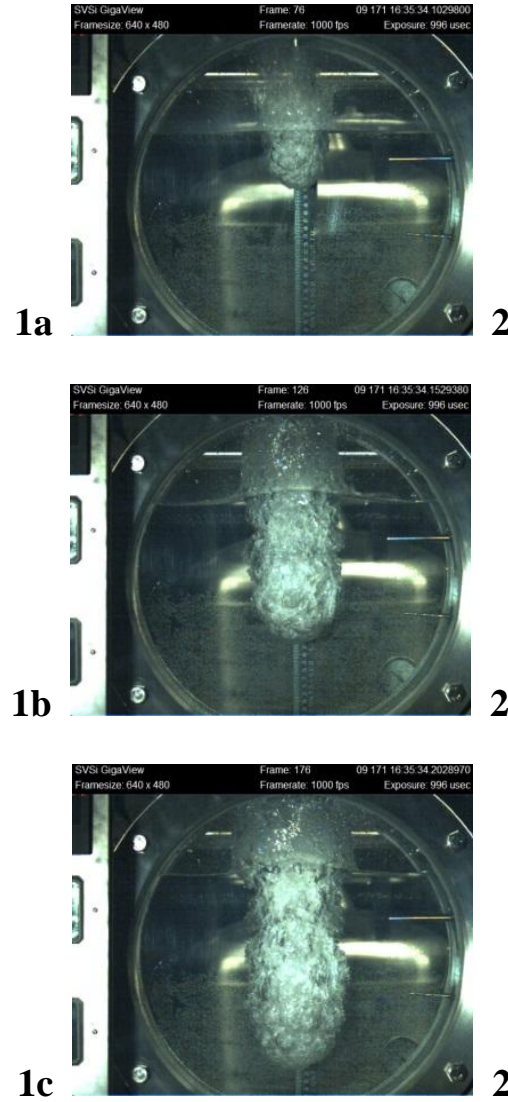

$2 \mathbf{b}$
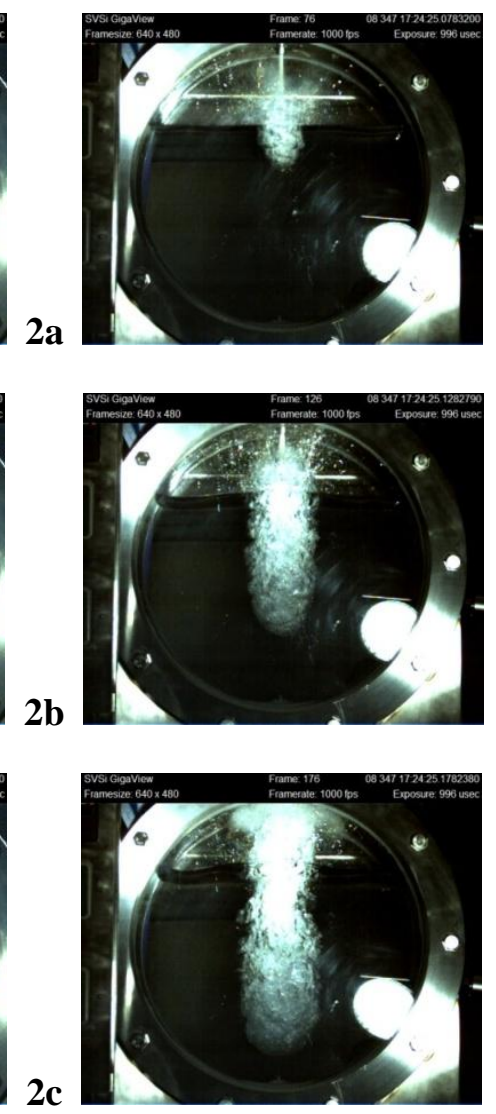

$3 \mathbf{b}$

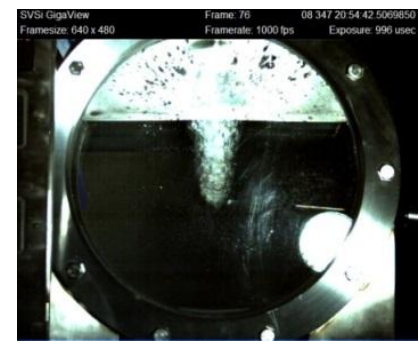

3a

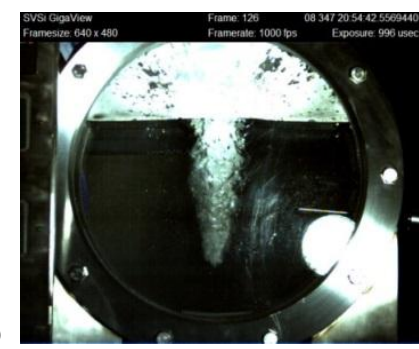

$3 c$
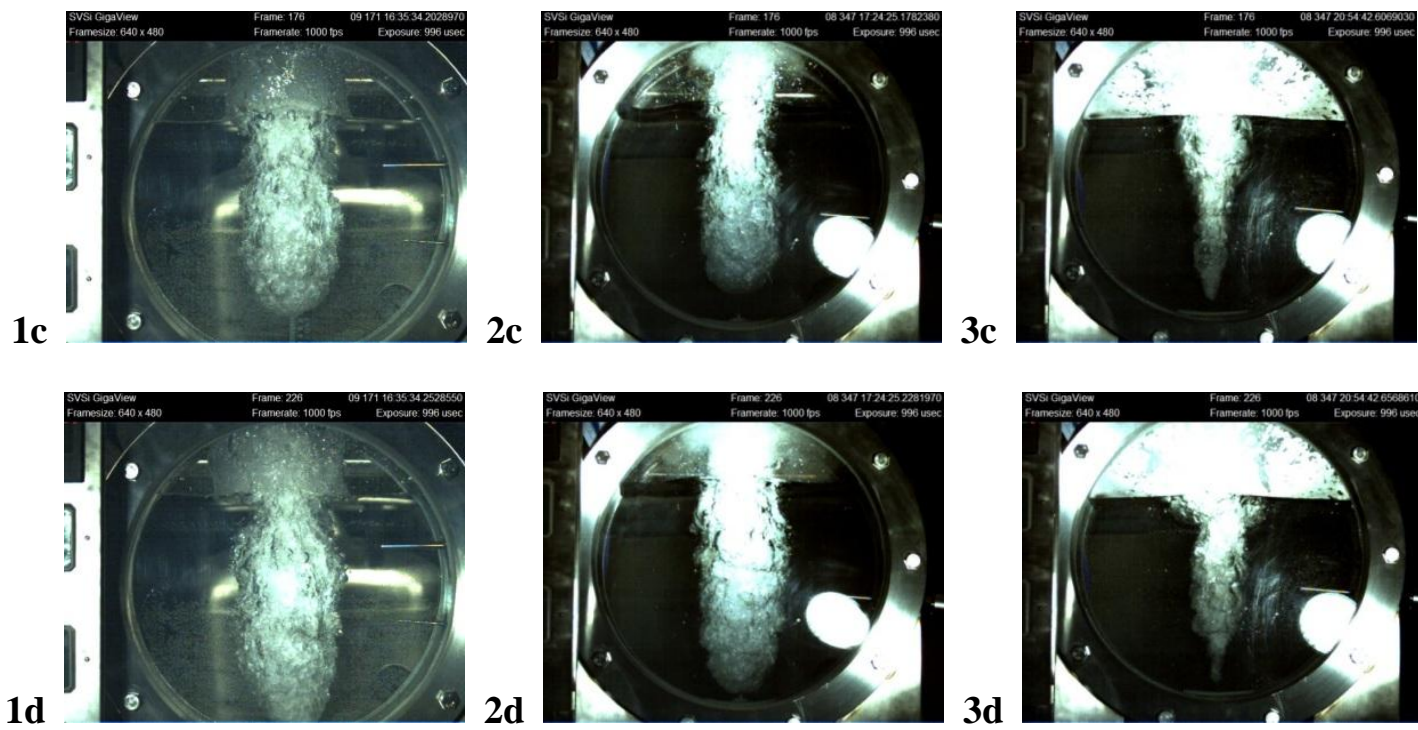

2d

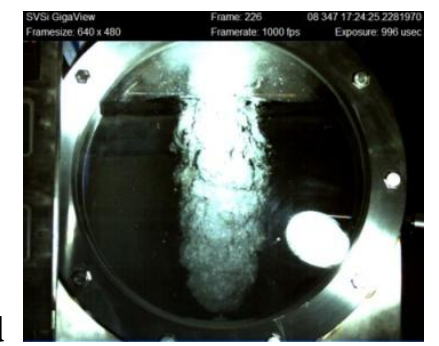

$3 d$

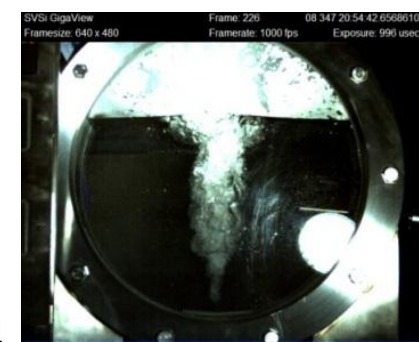



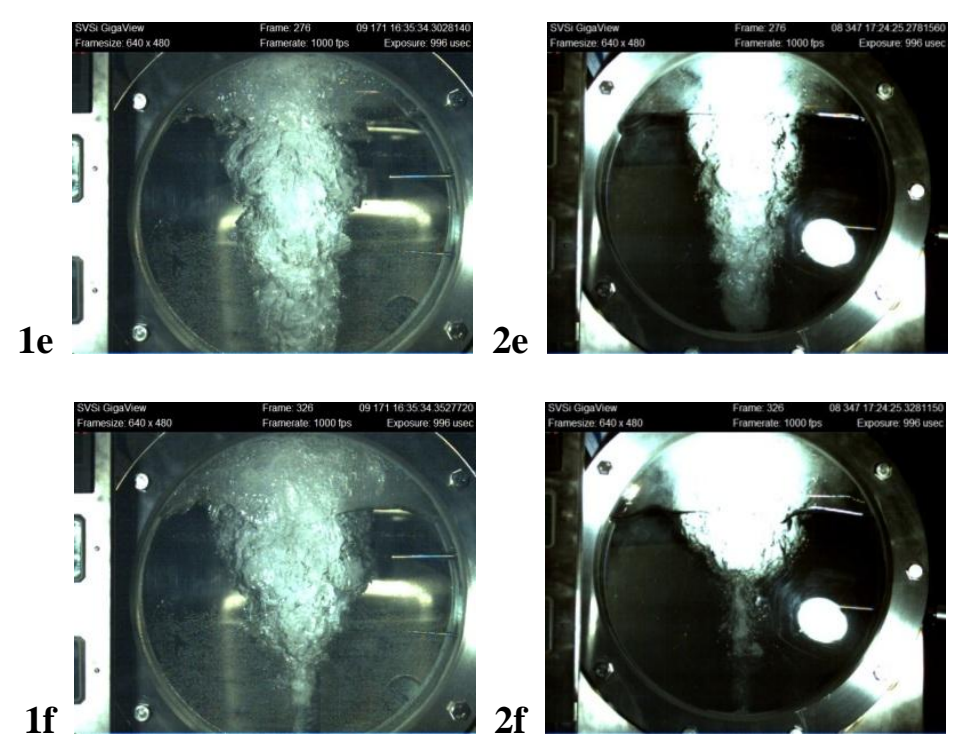
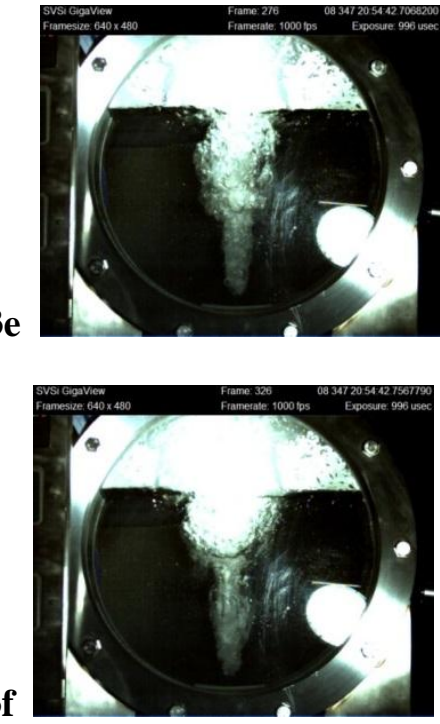

Figure 5. Bubble behaviors of cryogen injection into water (la lf are images of run $1,2 a \sim 2 f$ are images of run 6, 3a 3f are images of run 5. The interval time between the adjacent two images is $50 \mathrm{~ms}$ ).

\section{Conclusions}

The process of cryogen injection into water was studied experimentally and theoretically. Main conclusions can be drawn as following:

(1) There are four main instability theories used in analyzing cryogen injection into water process. If the relative velocity between cryogen and surrounding fluid is high enough, the breaking of liquid column or droplets will be defined by the Kelvin-Helmholtz instability and Weber number theory. Furthermore, strong Marangoni effect on vapor film breaking can be obviously observed at the beginning of column floating upwards or the ending of column going downwards. And the periphery of the vapor film near the head of column is considerably stronger than other regions in the effect of Marangoni convection.

(2) When LNG is injected into unconfined water in the pressure of 7bar, the explosive boiling remarkably occurs with high heat transfer performance. The maximum heat transferring flux can be over $1.9 \mathrm{MW} / \mathrm{m}^{2}$. It is $\sim 7.8$ times bigger than the theoretical limit of heat transferring flux of the pure liquefied methane nucleate boiling $\left(0.244 \mathrm{MW} / \mathrm{m}^{2}\right)$.

(3) Besides water temperature, both injection pressure and depth of injection into water influence explosive boiling occurring and its heat transfer performance.

(4) According to the images of bubble behaviors, $\mathrm{LNG}$ and $\mathrm{LN}_{2}$ injection processes undergo a similar boiling, that is explosive boiling, which is characterized by bubbles cloud that strengthens heat transferring rate. $\mathrm{LC}_{3} \mathrm{H}_{8}$ injection into water triggers subcooled flow boiling. There is no significant breaking on the liquid cryogen column and without bubbles cloud.

Acknowledgements. This research was financially supported by National Natural Science Foundation of China (51306026); Liaoning Provincial Natural Science Foundation of China (201602087) the Fundamental Research Funds for the Central Universities (3132016015) and (3132016350). 


\section{REFERENCES}

[1] Anees, M.M., Qasim, M., Bashir, A. (2017): Physiological and Physical Impact of Noise Pollution on Environment. Earth Science Pakistan. 1(1): 08-11.

[2] Ashraf M.A., Hussin N.H., Gharibreza M. (2017): Studies on the Removal of Heavy Metals from Aqueous Solution Using Immobilized Typha angustata L. Earth Science Pakistan. 1(1): 12-16.

[3] Awasthi, M.K. (2013): Viscous corrections for the viscous potential flow analysis Rayleigh-Taylor instability with heat and mass transfer. -Journal of Heat Transfer 135: 071701.

[4] Awasthi, M.K., Asthana, R, Agrawal, G.S. (2012): Pressure corrections for the potential flow analysis of Kelvin-Helmholtz instability with heat and mass transfer. -International Journal of Heat and Mass Transfer 55: 2345-2352.

[5] Byoung, J.K., Jong, H.L., Kyung, D.K. (2015): Rayleigh-Taylor instability for thin viscous gas films: Application for critical heat flux and minimum film boiling. -International Journal of Heat and Mass Transfer 80: 150-158.

[6] Clarke, H., Martinez-Herasme, A, Crookes, R., Wen, D.S. (2010): Experimental study of jet structure and pressurization upon liquid nitrogen injection into water. -Multiphase Flow 36: 940-949.

[7] Dahlsveen, J., Kristoffersen, R., Saetran, L. (2001): Jet mixing of cryogen and water. -2nd International Symposium Turbulence and Shear Flow Phenomena, 329-334.

[8] Deng Q., Yang K., Luo Y. (2017): Spatiotemporal patterns of PM2.5in the Beijing-Tianjin-Hebei region during 2013-2016. Geology, Ecology, and Landscapes. 1(2), 95-103.

[9] Enger, T. (1972): Explosive Boiling of Liquefied Gases on Water. -Proceeding of the conf. on LNG import and terminal safety. Boston.

[10] Garland, F., Atkinson, G. (1971): The Interaction of Liquid Hydrocarbons with Water. -Rpt. No. AD-753561, US DOT, USCG.

[11] Goldwire Jr, H.C., Rodean, H.C., Cederwall, R.T., et al. (1983): Coyote Series Data Report. LLNL/NWC 1981 LNG Spill Test Dispersion Vapor Burn, and Rapid Phase Transition. -UCID 19953.

[12] Hyun, G.L., Junseok, K. (2015): Two-dimensional Kelvin-Helmholtz instabilities of multi-component fluid. -European Journal of MechanicsB/Fluids 49: 77-88.

[13] Khan A.M., Noor M.J (2017): Radiocaesium contaminated sites and possible techniques for remediation. Geology, Ecology, and Landscapes. 1(2), 84-94.

[14] Koopman, R.P., Baker, J., Cederwall, R.T., et al. (1982): Burro Series Data Report. LLNL/NWC 1980 LNG Spill Test. -UCID 19075.

[15] Luketa-hanlin, A. (2006): A review of large-scale LNG spills: experiments and modeling. -Journal of Hazardous Materials 132: 119-140.

[16] Nail, S. K. (1999): Simulation of vapour explosions. -Applied Energy 64: 317-321.

[17] Nakanishi, E., Reid, R.C. (1971): Liquid Natural Gas-Water Reactions. -Chem. Eng. Progress 67: 36-41.

[18] Porteous, W.M., Blander, M. (1975): Limits of superheat and explosive boiling of light hydrocarbons, halocarbons and hydrocarbon mixtures. - AIChE J. 31: 560-566.

[19] Tang, J. G., Zhu, G. Y., Sun, L. C. (2013): Microbubble emission boiling in subcooled pool boiling and the role of Marangoni convection in its formation. -Experimental 
Thermal and Fluid Science 50: 97-106.

[20] Van, P.C. (1992): Liquid-vapor phase-change phenomena: An Introduction to the Thermophysics of Vaporization and Condensation Processes in Heat Transfer Equipment. -Hemisphere Publishing corporation, USA. pp: 311-318.

[21] Wen, D.S., Chen, H.S., Ding, Y.L., Dearman, P. (2006): $\mathrm{LN}_{2}$ injection intowater: pressure build-up and heat transfer. -Cryogenics 46: 740-748.

[22] Zhang, B., Yu, G.F., Wu, W.Q., et al. (2015): Experimental study on explosive boiling mechanism of LNG discharging on/under water. -Journal of Dalian Maritime University 41: 115-120.

[23] Zhang, B., Zhang, X.D., Wu, W.Q. (2016): Numerical and experimental study on LNG releasing underwater. -Journal of Residuals Science \& Technology 13: 189.1-189.6. 